\title{
Artificial neural network and regression-based models for prediction of surface roughness during turning of red brass $(\mathbf{C 2 3 0 0 0})$
}

\author{
M. Hanief* and M.F. Wani \\ Mechanical Engineering Department, NIT Srinagar, 190006, India \\ Email: hanief@nitsri.net \\ Phone+919906763424
}

\begin{abstract}
In this study, models based on artificial neural networks (ANN) and regression analysis were developed to predict the surface roughness during the turning of red brass (C23000), using a high-speed steel (HSS) tool. The full factorial design approach was used for experimentation to achieve a high level of confidence. The influence of cutting parameters (cutting speed, feed rate and depth of cut) on the surface roughness was also investigated using ANOVA. The ANN model having hyperbolic tangent sigmoid (tansig) and linear (purelin) transfer functions was used for the hidden and output layers respectively. The regression model based on the power law was also developed. It was found that at a speed of $840 \mathrm{~m} / \mathrm{sec}$ and depth of cut of $0.1 \mathrm{~mm}$, the surface roughness changed by $11.3 \%$ when changing the feed rate by $5.6 \%$. However, the surface roughness changed by only $6.8 \%$ when changing the velocity by $6 \%$ at the feed rate of $0.12 \mathrm{~mm}$ and depth of cut $0.1 \mathrm{~mm}$. A similar trend was observed for different feed rates, speeds and depths of cut. It was concluded that the feed rate was the most significant factor influencing the surface roughness, followed by the depth of cut and cutting speed. The models developed were compared using statistical methods: coefficient of determination $\left(\mathrm{R}^{2}\right)$ and mean absolute percentage error (MAPE). $\mathrm{R}^{2}$ was found to be 0.99784 and 0.9969 for the ANN and regression models, respectively. Similarly, MAPE was found to be $1.4243 \%$ and $4.8161 \%$ for the ANN and regression models respectively. It was concluded that the ANN model is a superior choice over the multiple regression model for the prediction of surface roughness. The accuracy of the ANN can be attributed to its ability to capture the nonlinearities involved in the turning operation.
\end{abstract}

Keywords: Artificial neural network; brass; regression analysis; surface roughness; turning.

\section{INTRODUCTION}

Brass and brass alloys are widely used as industrial materials because of their excellent characteristics such as high corrosion resistance, non-magnetism and good machinability [1]. It is necessary to achieve a desired surface topography of a mechanical component during the machining operation, as the surface roughness significantly influences its tribological properties during its useful life. A good surface finish improves the wear and friction characteristics and also increases the fatigue life of a component [2]. In order to achieve the desired surface finish, a good predictive model is required for stable machining [1]. The surface finish in turning has been found to be influenced to varying extents by the feed rate, work material characteristics, work hardness, unstable built-up edges, cutting speed, depth of cut, cutting time, tool-nose radius and cutting tool edge 
angles, stability of the machine tool and workpiece setup, chatter and use of cutting fluid [3]. Surface roughness is mostly based on the cutting parameters (cutting speed, feed rate, and depth of cut) and sometimes some other parameters [4]. In the literature, various models for the optimum surface roughness have been reported [5-10]. The feed rate was found to be the dominant factor among the cutting parameters (cutting speed, feed rate and cutting time) on the surface roughness and flank wear during the turning of AISI H11, using the response surface methodology (RSM) [11, 12]. Surface roughness was found to be influenced by the feed rate during the turning of mild steel with coated carbide tools using RSM [3]. Depth of cut was found to have an insignificant effect on the surface roughness during turning of AISI P20 using CVD and PVD coated carbide tools [4, 1214]. Several techniques have been used for the modelling and optimization of surface roughness during the turning operation, e.g. regression analysis, genetic algorithm, ANN, Taguchi method etc. A genetic algorithm approach was used for prediction of the surface roughness of mild steel in a turning operation $[5,15]$. Surface roughness during the turning of free machining steel [16] and AISI 4340 [17] was studied using ANN [16, 18, 19] and multiple regression [17], and it was found that the feed rate had the dominant influence, among the cutting parameters, on the surface roughness. During the machining of glass fibre reinforced plastic (GFRP) pipes using the response surface methodology and a carbide tool, four parameters (cutting speed, depth of cut, feed rate and fibre orientation) were selected. It was found that the depth of cut had the minimum effect on the surface roughness [20]. A correlation between cutting velocity, feed and depth of cut with the roughness evaluating parameters $R_{a}$ and $R_{t}$ was established using the Taguchi method [21]. A survey of the surface roughness prediction models developed and factors influencing surface roughness revealed that most of the surface roughness models were developed for steels [22]. Only a few references could be found in the literature where machining of brass has been investigated, e.g. [1] investigated the effect of machining parameters on the surface quality of brass (60/40) in CNC end milling using AFNIS modelling. Machining operations of steels have been investigated extensively, using different cutting tools and modelling techniques. However, alloys, particularly brass, have not been the focus of researchers as much as steels have been. The intention of the present research work was to develop a surface roughness prediction model and investigate the effect of cutting parameters during the turning of red brass (C23000) using regression analysis and ANN.

\section{METHODS AND PROCEDURES}

\section{Regression Model}

Surface roughness being a nonlinear function of cutting parameters [3, 16], we assume a power law model to take nonlinearity into account. The model of predicted surface roughness, $R_{a}$ can thus be expressed in nonlinear form as Eq. (1) [23]:

$$
R_{a}=k \prod_{i=1}^{n} p_{i}{ }^{c_{i}}
$$

where $p_{i}$, and $c_{i} i=1,2,3 \ldots n$ are the cutting parameters and model parameters respectively.

Eq. (1) can be rewritten as Eq. (2) [3]: 


$$
R_{a}=k p_{1}{ }^{c_{1}} p_{2}{ }^{c_{2}} p_{3}{ }^{c_{3}} \ldots \ldots . p_{n}{ }^{c_{n}}
$$

The parameters considered in the present study were the cutting speed $(v)$, feed rate $(f)$ and depth of cut $(d)$. Thus Eq. (2) can be rewritten as Eq. (3) [3]:

$$
R_{a}=k v^{c_{1}} f^{c_{2}} d^{c_{3}}
$$

Using logarithmic transformation, Eq. (3) can be rewritten as Eq. (4):

$$
\begin{gathered}
\ln R_{a}=\ln k+c_{1} \ln v+c_{2} \ln f+c_{3} \operatorname{lnd} \\
Y_{r}=c_{o}+c_{1} V+c_{2} F+c_{3} D
\end{gathered}
$$

where $Y_{r}=\ln R_{a}, c_{o}=\ln k, V=\ln v, F=\ln f, D=\operatorname{lnd}$.

The model parameters $k, c_{1}, c_{2}$ and $c_{3}$ in Eq. (5) were evaluated by the least squares method using Eq. (6) [24]:

$C=\left[Z^{T} Z\right]^{-1}\left[Z^{T}\right]\left\{Y_{r}\right\}$
where $C=\left\{\begin{array}{l}k \\ c_{1} \\ c_{2} \\ c_{3}\end{array}\right\}, \quad Z=\left\{\begin{array}{ccc}V_{1} & F_{1} & D_{1} \\ V_{2} & F_{2} & D_{2} \\ \cdots & \ldots & \ldots \\ \ldots & \ldots & \ldots \\ V_{N} & F_{N} & D_{N}\end{array}\right\}$ and $Y_{r}=\left\{\begin{array}{c}\left(\ln R_{a}\right)_{1} \\ \left(\ln R_{a}\right)_{2} \\ \left(\ln R_{a}\right)_{3} \\ \ldots \\ \ldots \\ \left(\ln R_{a}\right)_{N}\end{array}\right\}$

The value of $c_{o}$ is evaluated by back-substitution of $k$ into $c_{o}=e^{k}$. And finally, the model equation is obtained by substituting the values of $k, c_{1}, c_{2}$ and $c_{3}$ in Eq. (3).

\section{ANN Model}

ANN has been the focus of attention of researchers because of its capacity to solve nonlinear problems. Thus, ANN was also used to predict the surface roughness in the present study. An ANN model has several layers depending upon the nature and complexity of the problem [25]. The data from the input layer was processed in the hidden layer. The transfer function used in the hidden layer was hyperbolic tangent sigmoid (tansig), as in Eq. (7a). The output from the hidden layer was fed to the output layer having a linear transfer function (purelin) as in Eq. (7b):

$$
\begin{gathered}
F=\frac{e^{n}-e^{-n}}{e^{n}+e^{-n}} \\
f=n
\end{gathered}
$$

The weight changes were evaluated by Eq. (8). The weights were fed back after every iteration till the reduced error rate resulted in an improvement of the output of the training. The training was stopped when $R^{2}=1$ was attained.

$$
\Delta w_{j i}(n)=\alpha \Delta w_{j i}(n-1)+\eta \delta_{j}(n) R_{a_{i}}(n)
$$

where $\Delta w_{j i}(n)$ is the change in weights, $\alpha$ is the momentum coefficient, $\delta_{j}$ is the error scaled by the signal slope, $\eta$ is the learning rate parameter and $R_{a_{i}}(n)$ is the output after the $n^{\text {th }}$ iteration. The structure of the ANN model is shown in Figure 1. 


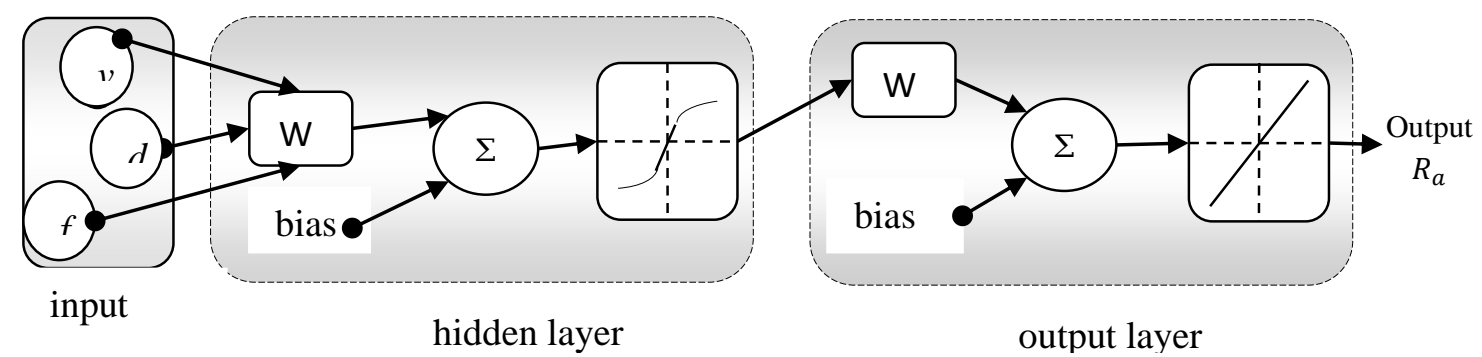

Figure 1. ANN architecture used for surface roughness modelling.

The first step in the ANN is training, in which the inputs, viz. cutting speed $(v)$, feed rate, $(f)$ and depth of cut, $(d)$, were introduced to the network along with the desired output of surface roughness. Initially, the weights were set randomly and were altered by a back-propagation algorithm to achieve a satisfactory level $\left(R^{2}=1\right)$ of performance by minimizing the global error. The back-propagation algorithm is a learning technique that adjusts weights in ANN by propagating weight changes in a backward direction (from the output to input neurons). When a satisfactory level of performance, i.e. coefficient of determination $R^{2}=1$, was achieved, the training was stopped and the network with current weights was used to predict the surface roughness. The parameters used for the ANN are tabulated in Table 1.

Table 1. Training parameters for ANN.

\begin{tabular}{ll}
\hline Number of neurons on the layer & Input: 3 , hidden: 5 and output: 1 \\
Initial weight and biases & Randomly between -1 and 1 \\
Activation function & Tansig \\
Learning rate & 0.05 \\
Momentum constant & 0.95 \\
\hline
\end{tabular}

Several independent runs having different initial random weights were performed to attain a solution with minimum error. The mean square error (MSE) during the learning process was calculated by Eq. (9) [26]:

$$
M S E=\frac{\sum_{i=1}^{N}\left|S_{i}-R_{a_{i}}\right|^{2}}{N}
$$

where $S_{i}$ and $R_{a_{i}}$ are the actual and predicted values of surface roughness. The weights between the hidden and output layers were adjusted and were again calculated using Eq. (8) [26].

\section{EXPERIMENTATION}

\section{Design of Experiments}

Design of experiments, usually abbreviated as DOE, are strategies developed for the model fitting of physical experiments. The objective of DOE is the selection of points where the response should be evaluated. The criteria for optimal design of experiments are associated with the mathematical model of the process. Generally, these mathematical models are polynomials with an unknown structure, so the corresponding experiments are 
designed only for every particular problem. The particular combination of runs defines an experimental design. The possible settings of each independent variable in the ndimensional space are called levels. A factorial experiment is an experimental strategy in which design variables are varied together, instead of one at a time. The three variables chosen in the turning operations were cutting speed, feed rate and depth of cut. Three operating levels were chosen as shown in Table 2. The experiments were performed by choosing one combination of cutting speed, feed rate and depth of cut. Two parameters were kept constant and the surface roughness was measured for three different values of the third parameter. Thus, according to the full factorial design, $27\left(3^{3}\right)$ were performed.

Table 2. Process parameters with different operating levels.

\begin{tabular}{lccc}
\hline \multicolumn{1}{c}{ Input parameters } & \multicolumn{3}{c}{ Levels } \\
\cline { 2 - 4 } & Level 1 & Level 2 & Level 3 \\
\cline { 2 - 4 } Cutting speed $(\mathrm{m} / \mathrm{sec})$ & 840 & 1000 & 1280 \\
Feed rate $(\mathrm{mm})$ & 0.12 & 0.40 & 0.80 \\
Depth of cut $(\mathrm{mm})$ & 0.10 & 0.13 & 0.16 \\
\hline
\end{tabular}

\section{Experimental Setup}

In this study, cylindrical red brass bars of diameter $30 \mathrm{~mm}$ and $150 \mathrm{~mm}$ length as the work piece material and an HSS cutting tool were used. The experiments were performed on a Kiloshkar Enterprise 1550 lathe under dry conditions. Two parameters were kept fixed and three experiments were performed for three different values of the third variable parameter. Accordingly, $27\left(3^{3}\right)$ experiments were performed. The parameters considered during the experimentation were feed rate, cutting speed and depth of cut. The surface roughness was measured by a Hommel Etamic WS roughness meter. The data obtained from the experiments are given in Table 3.

Table 3. Experimental data for model construction.

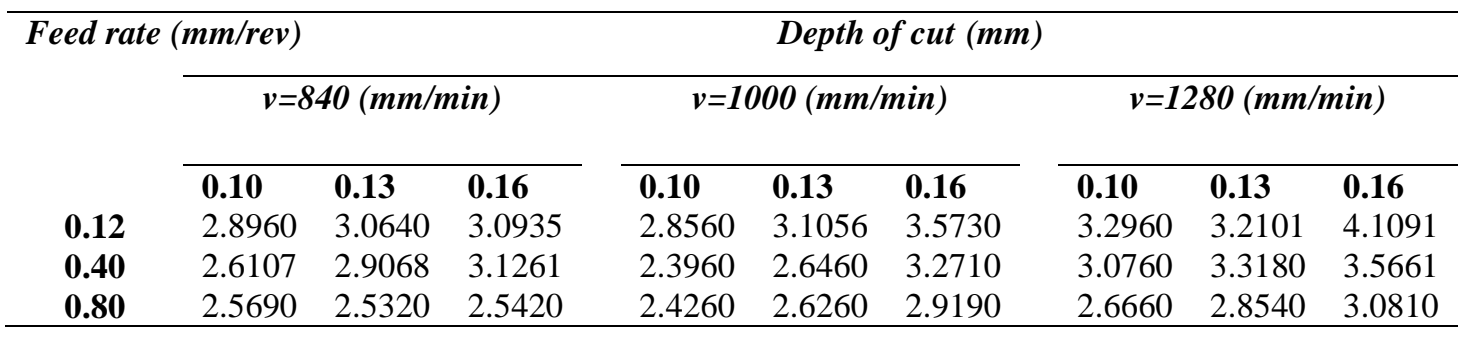

\section{RESULTS AND DISCUSSION}

\section{Regression Model for Surface Roughness}

The data presented in Table 1 were used for developing the model equation. The coefficients of the model equation were obtained by the least squares method using Eq. (6). Accordingly Eq. (9) was obtained.

$$
R_{a}=0.5179 v^{0.3378} f^{0.3419} d^{-0.0940}
$$


It is clear from Eq. (9) that the feed rate has the most significant effect on the surface roughness of red brass, followed by cutting speed and least by the depth of cut. Also, from Eq. (9) it is observed that the surface roughness decreases with increase in the depth of cut, while it increases with increase in the feed rate and cutting speed. A quantitative comparison between the current work and that from the literature was not possible as no work has been reported on the turning of red brass. It has been found for mild steel using a carbide tool that the surface roughness decreases with increase in the speed and depth of cut and decreases with decrease in the feed rate [27]. It has been reported that the feed rate has a significant effect on the surface roughness during the turning of brass [28], which has been observed in the present work also. This type of behaviour can be attributed to the brittleness of the red brass because the chips are not continuous as they are in the case of ductile materials. The comparison of the predicted and experimental values is shown in Figure 2.

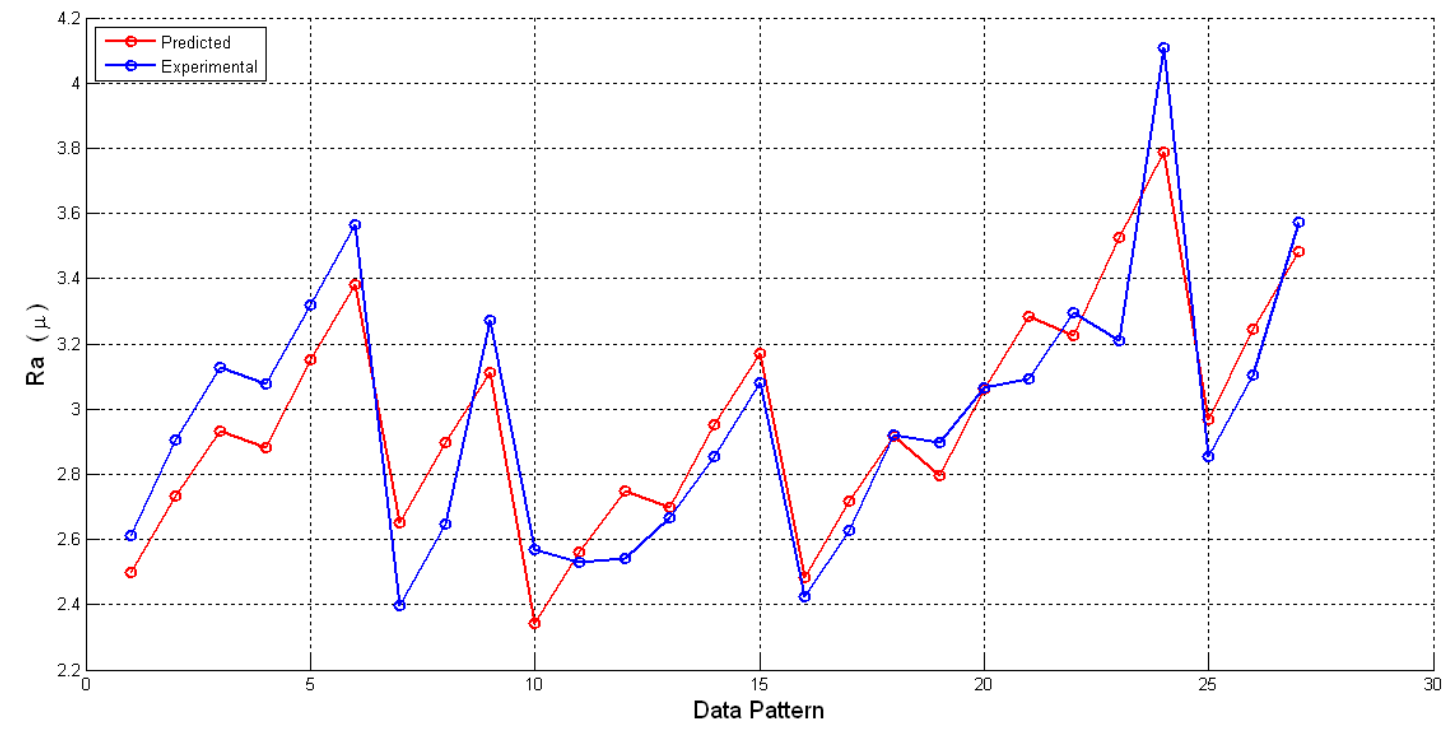

Figure 2. Measured and predicted values of surface roughness using regression model.

It is clear from Figure 2 that the experimental values are in close agreement with the values predicted by the regression method. The mean square error in the regression model was found to be 0.0280 . In order to check the adequacy of the proposed model, ANOVA was used. The results of the ANOVA are presented in Table 3. The F value of the regression model was found to be 35.02 and was compared with the standard tabulated value (4.76) for the confidence level of $95 \%$. The model was found to be adequate, as the value of $\mathrm{F}_{\text {critical }}$ is less than the $\mathrm{F}$ value obtained. Further, the $p$-value was found to be 0.01 and is lower than 0.05 (i.e. $\alpha=0.05$, or $95 \%$ confidence). This indicates that the model is statistically significant.

Table 3. ANOVA table for surface roughness ( $95 \%$ confidence level).

\begin{tabular}{lcccc}
\hline Source of variation & DF & SS & MS & F \\
\hline Regression & 3 & 3.3653 & 1.121 & 35.03 \\
Residual & 23 & 0.7547 & 0.032 & $\mathrm{~F}_{\text {critical }}=4.76$ \\
Total & 26 & 4.1200 & & \\
\hline
\end{tabular}




\section{ANN Model}

In order to develop the ANN model, the network was trained by a set of 14 values out of 27 experimental values. After successful training, the network was used to predict the surface roughness for validation and testing. The network was validated and tested for 5 (each) experimental values. From Figure 3, it is clear that during training all the experimental and predicted values coincide perfectly on the regression line, i.e. $R^{2}=1$. This indicates that the network was satisfactorily trained. At this stage, $R^{2}$ was found to be equal to 0.98766 and 0.99962 for validation and testing respectively. During testing and validation of the network, a few experimental values are slightly away from the regression line. Consequently, the value of $\mathrm{R}^{2}$ becomes slightly less than 1 and as a result $\mathrm{R}^{2}=0.99784$ for the ANN model. The training was stopped and all the 27 experimental values were used to predict the surface roughness from the ANN model.
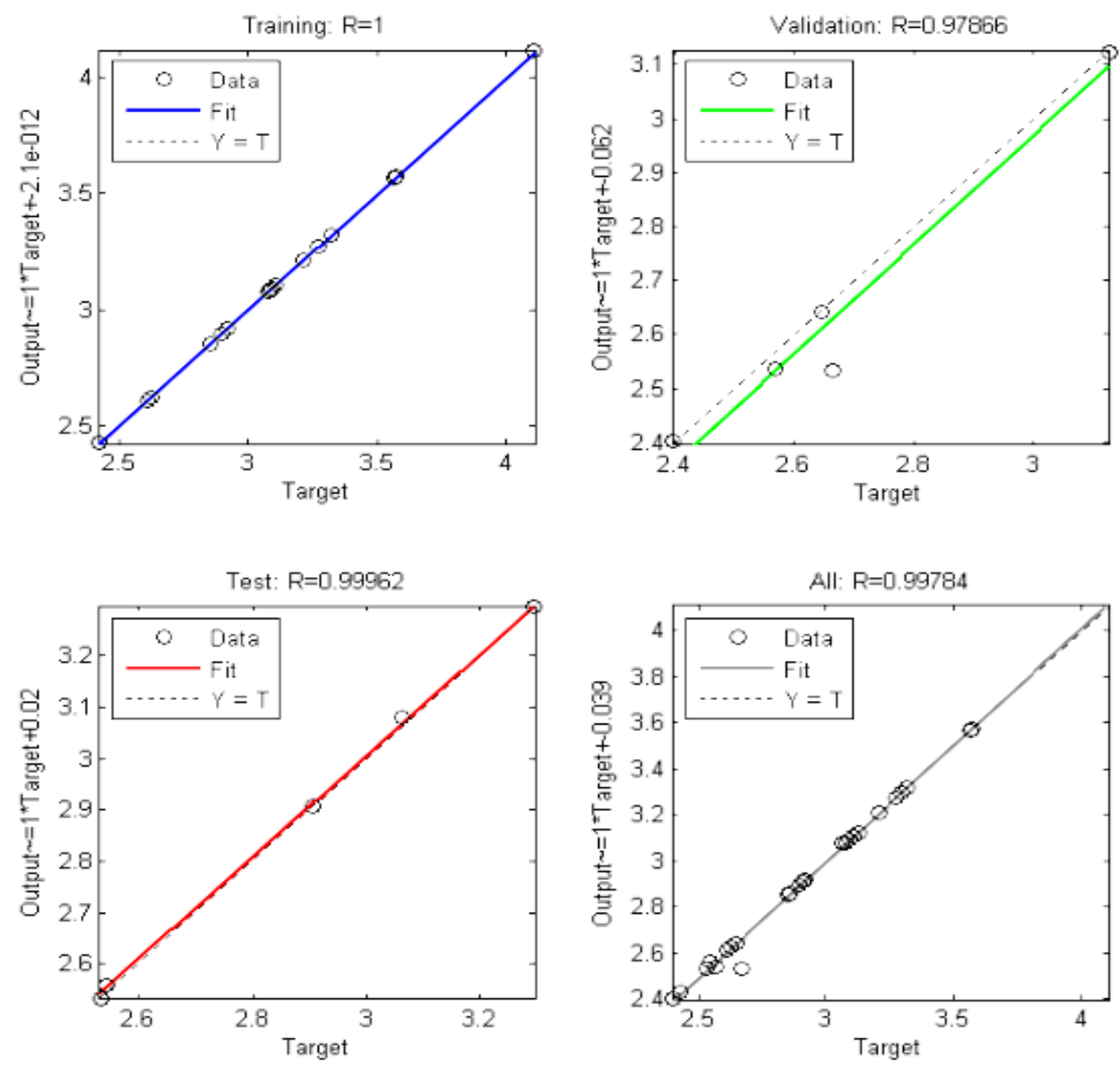

Figure 3. Target v/s output of the ANN model.

The comparison of the values predicted by ANN with the experimental values is shown in Figure 4. It is obvious that the error between the predicted and experimental values has been considerably reduced. The mean square error in the ANN model was found to be 0.0059 . The results obtained were compared with the experimental results using statistical methods ( $R^{2}$ and MAPE). $R^{2}$ is interpreted as the proportion of the variance in the dependent variable that is predictable from the independent variable [28]. 


$$
R^{2}=1-\left(\frac{\sum_{i=1}^{N}\left(t_{i}-o_{i}\right)^{2}}{\sum_{i=1}^{N}\left(o_{i}\right)^{2}}\right)
$$

The mean absolute percentage error (MAPE), also known as the mean absolute percentage deviation (MAPD), is a measure of the accuracy of a method for constructing fitted time series values in statistics, specifically in trend estimation, and is defined as [25]:

$$
M A P E=\left(\frac{1}{N} \sum_{i=1}^{N}\left|\frac{t_{i}-o_{i}}{t_{i}}\right|\right)
$$

where $N$ is the number of experiments.

Table 4. Comparison of ANN and regression model.

\begin{tabular}{cccc}
\hline Parameter & $\mathrm{R}^{2}$ & MSE & MAPE \\
\hline Regression model & $99.690 \%$ & 0.0280 & $4.8161 \%$ \\
ANN model & $99.784 \%$ & 0.0059 & $1.4243 \%$ \\
\hline
\end{tabular}

\begin{tabular}{|c|c|c|c|c|}
\hline \multirow[b]{2}{*}{ Exp.No } & \multicolumn{2}{|l|}{ ANN } & \multicolumn{2}{|c|}{ Regression } \\
\hline & Error & \%error & Error & \%error \\
\hline 1 & 0.0690 & 2.7621 & 0.1126 & 4.3113 \\
\hline 2 & 0.1747 & 6.3932 & 0.1742 & 5.9923 \\
\hline 3 & 0.1920 & 6.5446 & 0.1924 & 6.1552 \\
\hline 4 & 0.1971 & 6.8433 & 0.1958 & 6.3660 \\
\hline 5 & 0.0910 & 2.8884 & 0.1675 & 5.0480 \\
\hline 6 & 0.0992 & 2.9329 & 0.1838 & 5.1535 \\
\hline 7 & 0.2522 & 9.5181 & 0.2537 & 10.5892 \\
\hline 8 & 0.2514 & 8.6738 & 0.2524 & 9.5395 \\
\hline 9 & 0.1586 & 5.0969 & 0.1593 & 4.8707 \\
\hline 10 & 0.0913 & 3.9007 & 0.2284 & 8.8895 \\
\hline 11 & 0.0266 & 1.0389 & 0.0283 & 1.1183 \\
\hline 12 & 0.0010 & 0.0364 & 0.2067 & 8.1315 \\
\hline 13 & 0.0310 & 1.1487 & 0.0326 & 1.2219 \\
\hline 14 & 0.0967 & 3.2759 & 0.0979 & 3.4288 \\
\hline 15 & 0.0879 & 2.7737 & 0.0881 & 2.8580 \\
\hline 16 & 0.0547 & 2.2033 & 0.0566 & 2.3349 \\
\hline 17 & 0.1584 & 5.8328 & 0.0897 & 3.4143 \\
\hline 18 & 0.2060 & 7.0657 & 0.0035 & 0.1207 \\
\hline 19 & 0.0989 & 3.5354 & 0.0986 & 3.4061 \\
\hline 20 & 0.0041 & 0.1340 & 0.0041 & 0.1334 \\
\hline 21 & 0.1922 & 5.8507 & 0.1916 & 6.1923 \\
\hline 22 & 0.0108 & 0.3349 & 0.0708 & 2.1496 \\
\hline 23 & 0.3174 & 8.9969 & 0.3178 & 9.8986 \\
\hline 24 & 0.4379 & 1.1562 & 0.3217 & 7.8281 \\
\hline 25 & 0.1101 & 3.7107 & 0.1111 & 3.8895 \\
\hline 26 & 0.1399 & 4.3105 & 0.1400 & 4.5069 \\
\hline 27 & 0.2211 & 6.3454 & 0.0886 & 2.4804 \\
\hline
\end{tabular}

Table 5. Percentage error of ANN and regression model. 


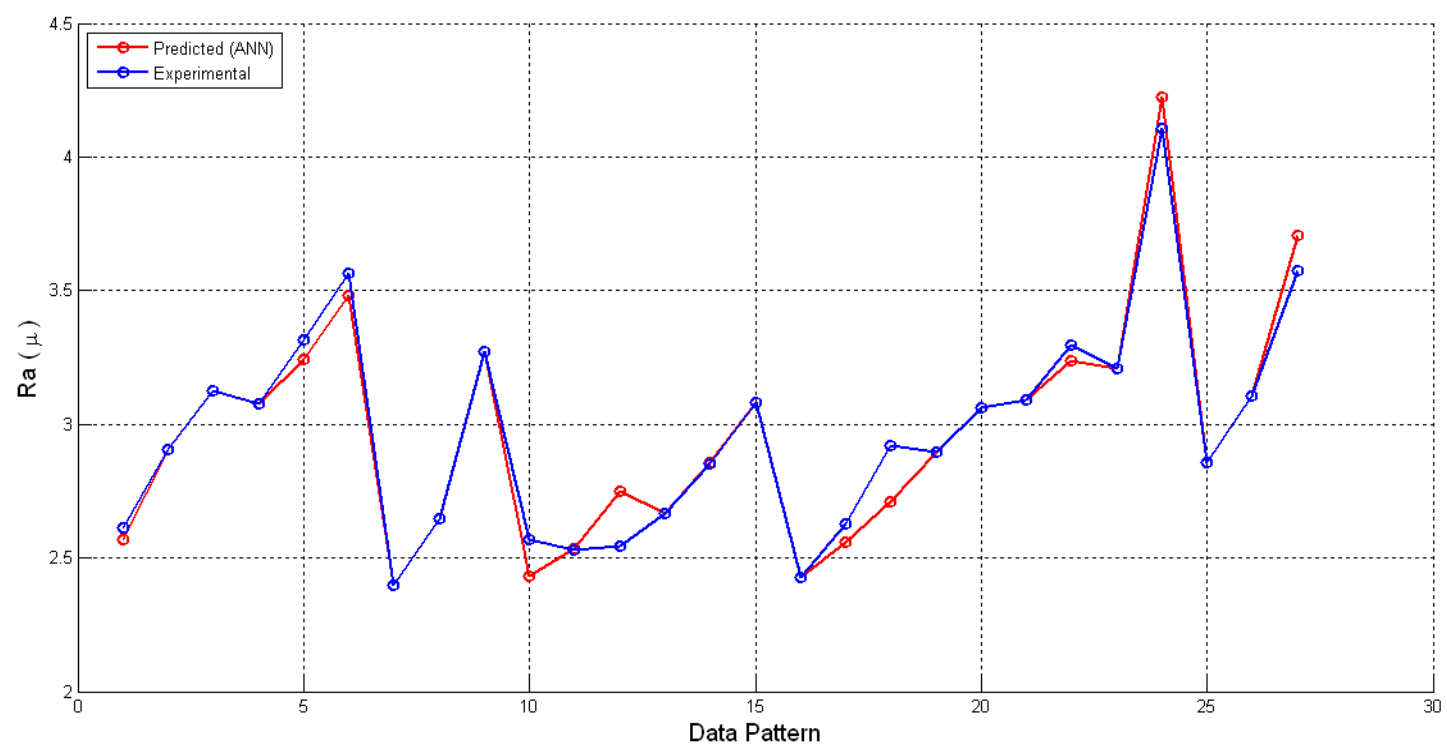

Figure 4. Measured and predicted values of surface roughness using ANN.

The percentage error of the ANN and regression models is presented in Table 5. It is clear from Table 5 that the maximum error in the ANN and the regression model is $9.5181 \%$ and $9.8986 \%$ respectively. Also, from Table 5 the minimum errors in the ANN and regression model are $0.0364 \%$ and $0.1207 \%$ respectively. On the basis of the $\mathrm{R}^{2}$, MAPE and errors evaluated, it can be stated that the ANN model gives more accurate results than the regression model.

\section{CONCLUSIONS}

In this paper, regression and ANN models were developed for the prediction of surface roughness in a turning operation of red brass. The DOE was based on the full factorial design methodology. Of the three cutting parameters (feed rate, cutting speed and depth of cut), surface roughness was found to be most significantly influenced by the feed rate and least by the depth of cut. It was also found that there is an increase in surface roughness with increase in the feed rate and cutting speed, whereas increase in the depth of cut decreases the surface roughness value. The developed models were evaluated for their capability to predict surface roughness on the basis of $\mathrm{R}^{2}$, MAPE and MSE. The $\mathrm{R}^{2}$ was $99.784 \%$ for the ANN and $99.69 \%$ for the regression model. It was concluded that the proposed models can be used effectively to predict surface roughness. Based on the percentage error of the ANN and regression model, the ANN was found to be more accurate than the regression model.

\section{ACKNOWLEDGEMENTS}

The authors would like to thanks to National Institute of Technology, Srinagar, J\&K India for their financial and institutional assistance. 


\section{REFERENCES}

[1] Maher I, Eltaib M, Sarhan AA, El-Zahry R. Investigation of the effect of machining parameters on the surface quality of machined brass (60/40) in CNC end milling-ANFIS modeling. The International Journal of Advanced Manufacturing Technology. 2014;74:531-7.

[2] Wang X, Feng C. Development of empirical models for surface roughness prediction in finish turning. The International Journal of Advanced Manufacturing Technology. 2002;20:348-56.

[3] Sahin Y, Motorcu AR. Surface roughness model for machining mild steel with coated carbide tool. Materials \& design. 2005;26:321-6.

[4] Cakir MC, Ensarioglu C, Demirayak I. Mathematical modeling of surface roughness for evaluating the effects of cutting parameters and coating material. Journal of Materials Processing and Technology. 2009;209:102-9.

[5] Suresh P, Rao PV, Deshmukh S. A genetic algorithmic approach for optimization of surface roughness prediction model. International Journal of Machine Tools and Manufacture. 2002;42:675-80.

[6] Nalbant M, Gökkaya H, Sur G. Application of Taguchi method in the optimization of cutting parameters for surface roughness in turning. Materials \& Design. 2007;28:1379-85.

[7] Günay M, Yücel E. Application of Taguchi method for determining optimum surface roughness in turning of high-alloy white cast iron. Measurement. 2013;46:913-9.

[8] Hasçalık A, Çaydaş U. Optimization of turning parameters for surface roughness and tool life based on the Taguchi method. The International Journal of Advanced Manufacturing Technology. 2008;38:896-903.

[9] Hamdan SH, Md Said AY, Biki JR. Surface Finish when Threading TitaniumBased Alloy under Dry Machining. Journal of Mechanical Engineering and Sciences. 2014;7:1062-9.

[10] Abu Bakar MH, Raja Abdullah RI, Md. Ali MA, Kasim MS, Sulaiman MA, Ahmad SSN, et al. Surface integrity of LM6 Aluminum metal matrix composite when machined with high speed steel and uncoated carbide cutting tools. Journal of Mechanical Engineering and Sciences. 2014;6:854-62.

[11] Aouici H, Yallese MA, Fnides B, Chaoui K, Mabrouki T. Modeling and optimization of hard turning of X38CrMoV5-1 steel with CBN tool: Machining parameters effects on flank wear and surface roughness. Journal of Mechical Science and Technology. 2011;25:2843-51.

[12] Rahman MM, Kadirgama K. Material removal rate and surface roughness on grinding of ductile cast iron using minimum quantity lubrication. International Journal of Automotive and Mechanical Engineering. 2015;11:2471-283.

[13] Yogeswaran M, Kadirgama K, Rahman MM, Devarajan R, Noor MM. Effect of $\mathrm{ZnO}$ nano materials on grinding surface finishing. International Journal of Automotive and Mechanical Engineering. 2015;12:2829-43.

[14] Razak NH, Rahman MM, Kadirgama K. Experimental study on surface integrity in end milling of Hastelloy C-2000 Superalloy. International Journal of Automotive and Mechanical Engineering. 2014;9:1578-87.

[15] Che Ghani SAB, Cheng K, Minton T. Back chip temperature in environmentally conscious turning with conventional and internally cooled cutting tools. Journal of Mechanical Engineering and Sciences. 2013;4:356-72. 
[16] Davim JP, Gaitonde V, Karnik S. Investigations into the effect of cutting conditions on surface roughness in turning of free machining steel by ANN models. Journal of Materials Processing Technology. 2008;205:16-23.

[17] Agrawal A, Goel S, Rashid WB, Price M. Prediction of surface roughness during hard turning of AISI 4340 steel (69 HRC). Applied Soft Computing. 2015;30:27986.

[18] Sahid NSM, Rahman MM, Kadirgama K. Neural Network Modeling of Grinding Parameters of Ductile Cast Iron Using Minimum Quantity Lubrication. International Journal of Automotive and Mechanical Engineering. 2015;11:260821.

[19] Supeni EE, Epaarachchi JA, Islam MM, Lau KT. Development of artificial neural network model in predicting performance of the smart wind turbine blade. Journal of Mechanical Engineering and Sciences. 2014;6:734-45.

[20] Hussain SA, Pandurangadu V, Palanikumar K. Surface roughness analysis in machining of GFRP composite by carbide tool (K20). European journal of scientific research. 2010;41:84-98.

[21] Davim JP. A note on the determination of optimal cutting conditions for surface finish obtained in turning using design of experiments. Journal of Materials Processing Technology. 2001;116:305-8.

[22] Mital A, Mehta M. Surface finish prediction models for fine turning. The International Journal Of Production Research. 1988;26:1861-76.

[23] Zain AM, Haron H, Qasem SN, Sharif S. Regression and ANN models for estimating minimum value of machining performance. Applied Mathematical Modelling. 2012;36:1477-92.

[24] Draper NR, Smith H. Applied regression analysis: John Wiley \& Sons; 2014.

[25] Hagan MT, Demuth HB, Beale MH, De Jesús O. Neural network design: PWS publishing company Boston; 1996.

[26] Asiltürk I, Çunkaş M. Modeling and prediction of surface roughness in turning operations using artificial neural network and multiple regression method. Expert Systems with Applications. 2011;38:5826-32.

[27] Vikram KA, Ratnam C, Narayana KS, Ben BS. Assessment of surface roughness and MRR while machining brass with HSS tool and carbide inserts. Indian Journal of Engineering \& Materials Sciences. 2015;22:321-30.

[28] Taghizadeh S, Safarian A, Jalali S, Salimiasl A. Developing a model for hardness prediction in water-quenched and tempered AISI 1045 steel through an artificial neural network. Materials \& Design. 2013;51:530-5. 